\title{
Recruiting patients cost-effectively by mail
}

\author{
Theingi Aung, Helen Cowan, Richard Haynes, Louise Bowman, Jane Armitage* \\ From Clinical Trials Methodology Conference 2011 \\ Bristol, UK. 4-5 October 2011
}

\section{Introduction}

Large randomised trials have been successfully conducted using mailed drug supply and follow-up [1-4] . ASCEND (A Study of Cardiovascular Events iN Diabetes) is a randomised " $2 \times 2$ factorial design" study of aspirin versus placebo and of omega- 3 fatty acid versus placebo, for the primary prevention of cardiovascular events in people with diabetes. In order to be able to study 15,000 people with diabetes for about 7 years at low cost, ASCEND is streamlined and run mainly by mail with back-up from a 24-hour Freefone service.

\section{Methods}

In collaboration with consultants around the UK, potentially eligible people with diabetes have been identified from various sources including: centrally-held registers (e.g.: Retinopathy screening registers); GP-held local registers and self-referral via a website. For patients identified from centrally-held registers, permission was gained from the National Information Governance Board to allow centrally generated letters in the name of the holder of the register, to be sent to patients listed on registers. In addition, with the collaboration of the Diabetes Research Network and the Primary Care Research Network, 730 general practices agreed to send preassembled invitation packs to people on their locally held registers.
To facilitate recruitment, the design is straightforward with simple inclusion and exclusion criteria and treatment packaged for easy mailing. Double sided A3 forms are used for screening, randomisation and follow-up. On the Screening form, patients confirm their eligibility and consent that they are happy to take part by ticking a series of boxes. If they have any questions then they can telephone study staff via a Freefone number. Screening forms of those entering the study are checked centrally by clinical staff. Patients enter a 2-month pre-randomisation run-in phase and are randomised if they complete a randomisation form and remain willing and eligible.

\section{Results}

In total, 423,286 people with diabetes were invited to take part and 15,481 randomised (see table).

\section{Conclusion}

If sufficient numbers of potentially eligible patients can be identified centrally and trial treatments require little in the way of monitoring, the recruitment and follow-up of patients in clinical trials by mail is feasible and costeffective. Wider use of these methods could allow more large randomised trials to be undertaken successfully and cost-effectively.

Published: 13 December 2011

Table 1

\begin{tabular}{lllll}
\hline & Centrally-held register & GP practices (Local register) & Others* & Total \\
\hline Invitations sent & 300,188 & 120,875 & 2223 & 423,286 \\
Patients enter run-in & 16104 & 9,741 & 635 & 26480 \\
Patients randomised & $9013(3.0 \%)$ & $6038(5.0 \%)$ & $430(19.3 \%)$ & $15481(3.7 \%)$ \\
\hline
\end{tabular}

* HPS follow up/Self/friends/Hospital referral 


\section{References}

1. Peto R, Gray R, Collins R, Wheatley K, Hennekens C, Jamrozik K, et al: Randomised trial of prophylactic daily aspirin in British male doctors. $\mathrm{Br}$ Med J (Clin Res Ed) 1988, 296(6618):313-6.

2. Final report on the aspirin component of the ongoing Physicians' Health Study. In N Engl I Med. Volume 321. Steering Committee of the Physicians' Health Study Research Group; 1989:(3):129-35.

3. Rexrode KM, Lee IM, Cook NR, Hennekens CH, Buring JE: Baseline characteristics of participants in the Women's Health Study. J Womens Health Gend Based Med 2000, 9(1):19-27.

4. Christen WG, Gaziano JM, Hennekens CH: Design of Physicians' Health Study II-a randomized trial of beta-carotene, vitamins E and C, and multivitamins, in prevention of cancer, cardiovascular disease, and eye disease, and review of results of completed trials. Ann Epidemiol 2000, 10(2):125-34.

doi:10.1186/1745-6215-12-S1-A117

Cite this article as: Aung et al:: Recruiting patients cost-effectively by mail. Trials 2011 12(Suppl 1):A117.

\section{Submit your next manuscript to BioMed Central} and take full advantage of:

- Convenient online submission

- Thorough peer review

- No space constraints or color figure charges

- Immediate publication on acceptance

- Inclusion in PubMed, CAS, Scopus and Google Scholar

- Research which is freely available for redistribution

Submit your manuscript at www.biomedcentral.com/submit 